\title{
Dos modalidades de participación ciudadana en política ambiental
}

\author{
Raúl Pacheco Vega* \\ Obdulia Vega López**
}

\begin{abstract}
In the sustainable development discourse, citizen participation is a common denominator, the foundation on which a nation's development is constructed in a sustainable manner (ecologically, economically and socially acceptable). There is a great diversity of participation modes. The purpose of this paper is to examine two modes of citizen participation in environmental policy making: the formation of environmental coalitions and consensus-building processes (multistakeholder roundtables or multistakeholder processes). Our thesis is that society has reclaimed its position in an incipient democracy, and that participation is a pre-requisite for sustainable development. We make a descriptive analysis of both techniques in the context of sustainability and we compare both modes to determine their relevance and the chances to apply either of them to environmental public policy in Mexico.
\end{abstract}

Keywords: citizen participation, coalitions, multistakeholder, sustainability, environment.

\section{Resumen}

En las discusiones sobre desarrollo sustentable, la participación ciudadana es el común denominador, el fundamento sobre el que se construye el desarrollo de una nación de manera sustentable (ecológica, económica y socialmente aceptable). Hay una gran diversidad de modalidades de participación. El propósito de este artículo es examinar dos modalidades de participación ciudadana en materia de política de medio ambiente: la formación de coaliciones ambientales y los procesos de construcción de consensos (mesas redondas multiparticipativas o procesos multiparticipativos). Nuestra tesis es que la sociedad ha reclamado su posición en una democracia incipiente, y que la participación es prerrequisito para un desarrollo sustentable. Hacemos un análisis descriptivo de ambas modalidades en el contexto de la sustentabilidad y comparamos las dos modalidades para determinar cuál es su relevancia y la posibilidad de aplicar cualesquiera de ambas al proceso de política pública ambiental en México.

Palabras clave: participación ciudadana, coaliciones, múltiples participantes, sustentabilidad, medio ambiente.

\footnotetext{
*University of British Columbia. Correo-e: pachecoh@interchange.ubc.ca

**Universidad de Guanajuato. Correo-e: ovega@ciatec.mx
} 


\section{Introducción ${ }^{1}$}

En el discurso sobre desarrollo sustentable, el concepto de participación ciudadana es elogiado como la piedra nodal sobre la que se puede fincar un modelo de desarrollo económicamente próspero, ecológicamente protector y socialmente aceptable. El involucramiento de la sociedad en la construcción, diseño e implantación de política ambiental no es ya una opción sino un prerrequisito si se habla de un desarrollo sustentable. La multidimensionalidad del paradigma de sustentabilidad no está en tela de juicio: las políticas públicas deben diseñarse de manera que la protección al medio ambiente se encuentre intrínsecamente ligada a los esquemas de crecimiento económico.

Ya ningún tipo de crecimiento puede denominarse sustentable si no involucra medidas de mitigación de daños ambientales. Sin embargo, a partir de fines de los años 80 y principios de los años 90, la participación ciudadana ha tomado una relevancia que anteriormente no tuvo: ahora el público no sólo quiere participar en el diseño de las políticas públicas en materia de medio ambiente, sino también en su implantación y evaluación, de manera que la participación ciudadana resulta una condición sine qua non para el éxito de los programas de protección del medio ambiente.

Existe una gran variedad de modalidades para la participación del público en la esfera política. En otros trabajos (VegaLópez y Pacheco-Vega, 2000 y 2001) hemos discutido el papel que tiene la participación ciudadana en el espectro de instrumentos de política ambiental de que disponen los gobiernos. ${ }^{2}$ Ahí hemos argumentado que la participación ciudadana está incluida (al menos en el ámbito conceptual) en leyes, programas y planes de desarrollo (en México, un ejemplo es la Ley General del Equilibrio Ecológico y la Protección al Ambiente).

Sin embargo, es poco discutido que dicha participación encierra una gran diversidad de conflictos, como consecuencia, un sinnúmero de preguntas salen a relucir: ¿Quién debe partici-

${ }^{1}$ Los autores agradecen los valiosos comentarios de dos dictaminadores anónimos y de Sigfrido Pacheco Vega. Asimismo agradecemos el apoyo, con información y sugerencias de Alejandro Natal, Rosario Rogel, Jacqueline Butcher de Rivas, José Aranda y Silvia Bolos. Todos los errores son obviamente nuestra responsabilidad. Raúl Pacheco agradece el apoyo del Conacyt en el periodo 1999-2002.

${ }^{2}$ La diversidad de instrumentos de política puede ser mapeada en un continuo de menor a mayor coerción, de menor a mayor involucramiento del gobierno y de menor a mayor centralización de la política (para una revisión de la teoría de selección de instrumentos, véase Vega-López y Pacheco-Vega, 2000). 
par en los procesos políticos? ¿Bajo qué modalidades debe darse esa participación? ¿Es realmente la democracia participativa un modelo realista en nuestra sociedad?

Más que pretender responder a todas estas preguntas (si bien importantes, demasiado amplias para ser discutidas a profundidad en este texto), en el presente artículo, nuestra intención es describir, a través de una revisión teórica de la literatura, únicamente dos modalidades de participación del público en materia de política de medio ambiente: la formación de coaliciones ambientales (CA) para la construcción de capital social -primordialmente a través de redes de organizaciones no gubernamentales (ONG) ambientalistas- y los procesos de construcción de consensos - mesas redondas multiparticipativas o procesos multiparticipativos (PMP). ${ }^{3}$

¿Por qué seleccionamos estas modalidades? En ambos casos, existe un fenómeno de inducción de cooperación. Las CA utilizan esquemas de cooperación y colaboración para conseguir sus metas, a través del diálogo e intercambio de recursos e información entre los miembros de la coalición. Los PMP se crean, generalmente, como resultado de la voluntad de un gobierno de escuchar la voz de la sociedad, mediante la selección de representantes (participantes) en la mesa redonda; en ese esquema, el gobierno y los ciudadanos cooperan hacia un mismo fin. Por su propia naturaleza (ya que son iniciados por el gobierno), los PMP gozan del potencial para ejercer un nivel de influencia muy alto sobre las decisiones gubernamentales, si bien no siempre este potencial llega a realizarse.

Otras modalidades (como jurados ciudadanos, referenda, células de planeación, etcétera) utilizan esquemas de tipo más institucionalizado, y en ocasiones menos flexibles. En cambio, las CA y las mesas redondas multiparticipativas son el resultado de esfuerzos cooperativos (si bien dicha cooperación es inducida) en los que el grado de colaboración es notable.

Sin embargo, la gran diferencia entre ambas modalidades yace en los mecanismos de transmisión de presión social que las organizaciones involucradas en estos procesos utilizan para allegarse recursos y lograr sus objetivos. Mientras que las CA utilizan mecanismos de presión social, los PMP tienen una diversidad de

\footnotetext{
${ }^{3}$ El término "procesos multiparticipativos" proviene del término en inglés multistakeholder process. Dado que no existe una traducción directa del término stakeholder (participante), hemos optado por mantener la nomenclatura propuesta por Vega-López (1999).
} 
mecanismos de inducción del cambio (que pueden incluir a la presión social, mas no se circunscriben exclusivamente a ésta). La modificación de la conducta gubernamental (y de los otros actores involucrados en el proceso de construcción de política pública para el medio ambiente) proviene de fuentes diferentes en cada caso.

El modelo tradicional de política ambiental, que trabaja bajo un esquema de tipo proteccionista ambiental, tiende a tratar los síntomas de un mal manejo ambiental (la contaminación) en lugar de atacar las causas (incorrecta planeación, falta de capital, desconocimiento y tecnologías inadecuadas). Por ello, el reto para los gobiernos radica en que las empresas nacionales sean lo suficientemente dinámicas como para mantener una operación que genere utilidades sin perjuicio del medio ambiente, y esto sólo será posible si se involucra a los distintos intereses relevantes en el proceso de elaboración de políticas ambientales.

Las dos modalidades de participación ciudadana en política pública ambiental examinadas en este artículo están fundamentadas en actitudes de tipo voluntario (en el caso de las coaliciones de ONG) y de cooperación (en el caso de los PMP, donde cada uno de los afectados por un proyecto participa en la toma de decisiones). ${ }^{4}$ Dichas actitudes forman parte de un nuevo paradigma de sustentabilidad: la participación hacia la construcción de un futuro común (WCED, 1987).

El artículo está organizado de la siguiente manera: iniciaremos examinando las diferentes definiciones de participación pública y las escalas de participación en la construcción de política ambiental. Analizamos el reciente fenómeno de incremento en la participación ciudadana y las diversas modalidades de participación. Argumentamos que la sociedad ha reclamado su posición en una democracia incipiente y que la participación es prerrequisito no sólo en el ámbito sociopolítico, sino también en la esfera del desarrollo sustentable. Bajo el mismo esquema, discutimos el papel de la participación ciudadana en el ciclo de la política ambiental, iniciando con el establecimiento de la agenda pública y terminando con el proceso de evaluación post-implantación. Los mecanismos de participación examinados (PMP y CA) se encuen-

\footnotetext{
${ }^{4} \mathrm{El}$ afectado, interesado o participante en las mesas redondas se denomina stakeholder, ya que es quien tiene un interés en el asunto (stake). Este término proviene de la antigua tradición de apuestas en las corridas de caballos y ha devenido para convertirse en la palabra clave para denotar aquellos individuos, grupos o coaliciones de individuos que tienen un interés en el asunto a tratar (véase Vega-López, 1999).
} 
tran incrustados en el espectro de opciones de política pública disponibles para los gobiernos. En la siguiente sección, hacemos un análisis de los diversos esquemas de instrumentos de política (sustantivos y de procedimientos), y enmarcamos a los PMP y las CA en esta tipología analítica. Ofrecemos un espectro de modalidades de participación en el que los PMP y las CA tienen una relevancia particular. En una sección posterior, ofrecemos un tratamiento teórico de los PMP y las CA a través de una diversidad de esquemas analíticos, entre los que se encuentra la teoría democrática, la teoría de los nuevos movimientos sociales (TNMS) y la teoría de movilización de recursos (TMR). Finalmente, concluimos con una reivindicación de estas dos modalidades de participación ciudadana con la esperanza de que puedan ser utilizadas a futuro en la construcción de una política ambiental sustentable.

\section{Democracia y participación ciudadana}

Como bien afirma Enrique Cabrero (2000), el gran supuesto de las políticas públicas en la actualidad (como resultado de la tradición democrática) es que la participación ciudadana es un prerrequisito para la democracia. Sin embargo, para Cabrero, las políticas así conformadas son más gubernamentales que públicas. ${ }^{5}$ En este caso no haremos dicha distinción. Para efectos de nuestro análisis, las políticas cuyo objetivo sea atacar problemas de la sociedad de manera uniforme serán políticas públicas. Sin embargo, del mismo modo que existen discrepancias de opinión respecto de lo que es o no público, también hay diferencias entre lo que es la participación pública y lo que no lo es. Existen diversas definiciones de participación pública. Muy interesantes son las propuestas por Thomas (1995) y por Renn, Webler y Wiedemann (1995). Renn et al. (1995: 2) quienes definen participación pública como "foros para el intercambio que son organizados con el propósito de facilitar la comunicación entre el gobierno, los ciudadanos, los interesados y los grupos de interés, así como los intereses económicos en relación con un problema”. Debemos hacer notar que Renn y sus coautores utilizan "participación pública" e "involucramiento del público" de manera indistinta. También es interesante notar que, en su definición, el término stakeholder o "afectado/participante" no parece abarcar el rango más

\footnotetext{
${ }^{5}$ Cabrero hace una excelente argumentación a este respecto. Sin embargo, nosotros nos avocaremos a utilizar la frase "política pública" en el contexto de una política gubernamental o de Estado de igual manera.
} 
amplio de constituencias ${ }^{6}$ con un interés en el resultado de un proceso de decisión. Para efectos de este artículo, usamos stakeholder o "participante" en el sentido más amplio.

La definición de Thomas de participación ciudadana (donde los ciudadanos también son participantes/afectados) es diferente del involucramiento público "tradicional". Thomas plantea que el nuevo involucramiento público se enfoca "directamente en la implementación de la política, en involucrar al público en la decisión de cómo poner en operación las políticas que se han adoptado" (Thomas, 1995: 3). Como resultado, su decisión parece maximizar el ámbito de la participación del público. Mientras que anteriormente el público era sólo consultado, la nueva participación ciudadana deberá ser aquella en la que el público esté involucrado en todas las etapas del ciclo de política.

La participación en ejercicios de solución de conflictos de naturaleza pública ${ }^{7}$ que utilizan instrumentos de política de tercera generación (Vega-López y Pacheco-Vega, 2000; Pacheco y Nemetz, 2001) parece haber evolucionado como respuesta a la búsqueda incesante de un régimen democrático y efectivo que sea capaz de confrontar problemas y conflictos ambientales que resultan ser bastante complejos, y que no son fáciles de resolver por métodos de análisis unidisciplinares, sino a través de una perspectiva multidisciplinaria. Es por ello que la participación ciudadana ayuda a mejorar la calidad de las decisiones tomadas en aspectos de medio ambiente. Al ser el resultado de deliberaciones de todos los miembros que tienen un interés en el problema, es más fácil poder detectar las áreas de oportunidad en las que haya necesidad de trabajar. Como dice el viejo adagio: 'dos cabezas piensan mejor que una'.

En gran parte, los ejercicios de participación del público en el ciclo de construcción de política son el resultado de la búsqueda de una solución satisfactoria a los problemas de asimetría de información. Dado que no todos los participantes en los ejercicios de consulta tienen toda la información a la mano, estos ejercicios permiten ofrecer un espacio de diálogo y consulta en el que el intercambio de información beneficia a todos los participantes.

${ }^{6}$ La definición coloquial de constituencia es: conglomerado de partes afectadas, es decir, personas que comparten la necesidad de pertenecer a un grupo, que tienen un interés en un asunto, y que comparten una problemática.

${ }^{7}$ Es importante hacer notar que el carácter intrínseco del medio ambiente como un 'bien público' (de acuerdo con la teoría microeconómica neoclásica) hace que los conflictos relacionados con aspectos ambientales sean también de naturaleza pública. 
Los diversos retos que las sociedades democráticas modernas encaran han forzado a los burócratas y políticos encargados del medio ambiente a innovar y tratar de diseñar nuevas estrategias para hacer frente a dichos retos. Nosotros argumentamos que tres debilidades primordiales en los modernos sistemas de gobierno parecen ser las responsables del incremento en la utilización de novedosos instrumentos de política pública (alternativos a una regulación estricta).

\subsection{Fallas gubernamentales}

Existe una corriente teórica (primordialmente de economistas y científicos políticos de la escuela estadounidense) que argumenta que la intervención del gobierno en los asuntos públicos deriva de una falla de los mercados (Weimer y Vining, 1989). Cuando las transacciones basadas en el mercado fallan en su intento por producir resultados satisfactorios para todos los actores involucrados, se genera una falla del mercado, lo cual ocasiona que el gobierno intervenga. Por ejemplo, la contaminación ambiental ha sido tratada como una externalidad (una falla de mercado) por la teoría microeconómica clásica. Dado que el medio ambiente es un bien público (una forma de falla de mercado), es función del gobierno determinar los niveles de acceso a los recursos de cada uno de los actores involucrados. Sin embargo, como la experiencia ha demostrado, dicha intervención no siempre produce resultados eficientes o mucho menos, deseables. Por lo tanto, las fallas de mercado pueden originar fallas gubernamentales, lo que genera una necesidad de desarrollar mecanismos alternativos para la solución de conflictos públicos. Dukes sigue una línea de argumento similar cuando discute el concepto de crisis de gobierno en su trabajo sobre el enfoque transformativo de resolución de conflictos públicos (Dukes, 1996), donde teoriza sobre tres categorías específicas de problemas fundamentales que encaran las sociedades democráticas modernas:

- Desintegración de la comunidad;

- Alienación de las instituciones y prácticas de gobierno;

- Incapacidad para resolver problemas y conflictos públicos.

$\mathrm{Su}$ argumento es que un enfoque transformativo en cuanto a la solución de conflictos públicos (que permita una profunda integración de la comunidad hacia las instituciones de gobierno $y$ genere una verdadera toma de decisiones compartida) sería pri- 
mordial para resolver los problemas públicos. A través de este enfoque transformativo, Dukes diseña un nuevo rol para la práctica de solución de conflictos públicos que pudiera proveer cierto nivel de apoyo para resolver dilemas ambientales y conflictos de interés.

\subsection{La necesidad de legitimar a las políticas públicas}

Puesto que la legitimación de la política ambiental requiere el involucramiento de la ciudadanía afectada en el diseño de la solución, la participación ciudadana es vista como un agente legitimador (Renn et al., 1995). Como parte de esta visión, ha habido una serie de intentos para evaluar los pros y contras de los modelos de acción participativa. Sin embargo, se ha logrado poco éxito en la empresa ya que los criterios de evaluación son altamente subjetivos, y se genera el problema de falta de causalidad (el escenario común o previo a la puesta en marcha del ejercicio participativo) cuando se trata de establecer relaciones causales entre el nivel de participación ciudadana y el mejoramiento ambiental. Existen diversas modalidades de participación (comités o consejos ciudadanos, celdas de planeación, jurados ciudadanos, etcétera).

\subsection{El grito de la democracia}

El enunciado de Dietz (citado en Renn et al., 1995: XVII) con relación a lo siguiente: "[la] democracia es un modo antiguo de toma de decisiones sociales que tiene sus raíces en los elementos fundamentales de adaptación humana -comunicación y aprendizaje social" es primordial si queremos entender por qué los ciudadanos en una sociedad democrática quieren hacer oír su voz en la construcción de política pública ambiental. Si es el público quien tiene que vivir diariamente con las decisiones gubernamentales y adaptarse a ellas, entonces dichas decisiones tienen que ser comunicadas, difundidas y validadas por todos los miembros de la sociedad (y en el caso de una democracia, a través de sus representantes). Este es un proceso de aprendizaje social que ocurre día a día. Sin embargo, aun en las democracias occidentales, no siempre los ciudadanos son consultados, lo cual rompe las reglas básicas de una toma de decisiones pluralista y democrática. Por tanto, es necesario hacer uso de mecanismos innovadores que permitan a los ciudadanos adquirir poder (empowerment) 
para tener impacto en el diseño de política pública. Por tanto, los instrumentos de política pública de tercera generación se están empleando para mejorar los procesos de toma de decisiones, a fin de convertirla en una responsabilidad compartida entre los diversos miembros de la sociedad, oficiales gubernamentales, representantes de la industria, etcétera.

Dukes (1996) atribuye el incremento en el uso de estos novedosos instrumentos de participación ciudadana a la naturaleza intrínseca de las sociedades democráticas contemporáneas. Bajo un mecanismo de regulación social, como los de tercera generación, se propicia una arena de política pública dentro de la cual las estructuras del Estado, los mercados privados y la democracia colisionan. Por ende, las instituciones políticas actuales fallan en su objetivo de coordinar y armonizar un diálogo entre intereses que se encuentran opuestos por naturaleza. Estos mecanismos de participación permiten acceder a soluciones viables para establecer este nivel de diálogo entre ciudadanos y agencias gubernamentales.

Por ende, los esfuerzos de colaboración podrían ser el resultado de un sistema democrático que, a fin de ser efectivo, reconoce la necesidad de optar por colaborar en lugar de establecer conflictos en la arena de política ambiental. Sin embargo, la evidencia empírica y la literatura que hemos analizado parecen indicar que más que emanar directamente de la democracia como un régimen político, los mecanismos de colaboración (instrumentos suasivos) emergen de la falla de sistemas tradicionales de democracia representativa. ${ }^{8}$ Por ejemplo, los sistemas democráticos representativos tradicionales donde los representantes (diputados, senadores, miembros del Gabinete) son electos a las cámaras de senadores y diputados, o a puestos de elección popular son aparentemente incluyentes; sin embargo, la mayor parte del tiempo parecen haber fallado a las grandes esperanzas puestos en ellos. Por ende, los nuevos instrumentos de participación ciudadana pueden ayudar a resolver conflictos que anteriormente se veían como irresolubles. ${ }^{9}$

\footnotetext{
${ }^{8}$ Un excelente artículo sobre los límites de la Reforma del Estado y la democracia participativa es el trabajo de José Luis Méndez (1996).

${ }^{9}$ Es de hacer notar, sin embargo, que la participación ciudadana tiene sus límites. Una excelente argumentación al respecto la proporciona Rodolfo Canto Sáenz (2000).
} 


\section{Participación ciudadana e instrumentos de política pública}

Hemos identificado en otros trabajos cinco etapas primordiales en el proceso de construcción e implantación de políticas ambientales, siguiendo el modelo del ciclo de política pública (VegaLópez y Pacheco-Vega, 2000). En el marco de la sustentabilidad, la participación de la sociedad en todas y cada una de dichas etapas es altamente relevante, ya que el desarrollo sustentable requiere de analizar las dimensiones ecológica, política y social simultáneamente. Sin embargo, las modalidades en las que participa la ciudadanía y los instrumentos de política pública a que recurre son muy variados. También puede parecer paradójico que la participación ciudadana sea considerada como un instrumento de política pública y, al mismo tiempo, los ciudadanos puedan hacer uso de instrumentos de política. Procederemos a aclarar nuestra perspectiva analítica.

Los gobiernos (en este caso, los gobernantes) seleccionan opciones de política pública de entre una gama existente. Por ejemplo, un gobierno puede seleccionar un impuesto para minimizar la contaminación ambiental, establecer una sanción administrativa o penal para aquellas plantas industriales que contaminen, o establecer una campaña de educación ambiental con el fin de que las empresas dejen de ejercer daños sobre el medio ambiente. Todas son opciones de política pública, sin embargo, todas tienen diversos efectos sobre el comportamiento tanto del grupo objetivo (la industria) como de los actores externos asociados con éste (la sociedad, organizaciones no gubernamentales, etcétera). Al analizar la teoría de instrumentos de política, es posible describir y entender las decisiones de los gobiernos al seleccionar un instrumento de política pública sobre otro.

Definimos un instrumento de política pública como aquella actividad o programa utilizado por los actores políticos para modificar los procesos sociales. En este caso, el actor político debe cubrir dos características como prerrequisitos para poder influir en los procesos sociales: primero, tener autoridad para poder influir en procesos sociales; en segundo lugar, tener legitimidad para efectuar cambios sociales. El único actor político con autoridad y legitimidad inherente para efectuar dichos cambios es el gobierno; por ello, de manera inherente la selección de instrumentos de política es una tarea gubernamental. Ello no quiere decir que si las ONG o la sociedad civil o la industria desean modificar los procesos sociales, sus quehaceres sean ilegítimos. No 
obstante, la autoridad para regular funciones sociales está investida en el gobierno (la razón por la que votamos por un representante gubernamental es, precisamente, para que el representante vea por nuestros intereses como sociedad). Por ejemplo, la función de la policía es regular los procesos de convivencia social y proteger a la ciudadanía contra aquellos que violan dicha convivencia armónica. La función de las agencias de protección ambiental es legítima, ya que la protección del medio ambiente es una función de regulación social.

Sin embargo, puede parecer incongruente decir que la participación ciudadana es factible mediante distintos instrumentos de política ambiental, o que incluso la participación pueda ser un instrumento de política. De Bruijn y Hufen (1998) mencionan que los instrumentos de política comparten características de actividad y de objeto. Los instrumentos son objetos cuando nos referimos, por ejemplo, a la legislación. O pueden ser actividades, ya sean formales o informales, que afectan un proceso social. A partir de esta definición podemos inferir que también los ciudadanos pueden afectar los procesos sociales a través de su influencia sobre el gobierno. De esa manera, también la participación ciudadana es un instrumento de política y, simultáneamente, los ciudadanos pueden hacer uso de diversos instrumentos de política (aun cuando, por razones obvias, los instrumentos regulatorios o financieros están fuera del alcance). ${ }^{10}$

Más aún, en una versión más refinada de instrumentos de política, Howlett (1999) hace una distinción entre instrumentos sustantivos e instrumentos procedurales, en donde los instrumentos procedurales tienen como objetivo manipular los procesos de política, y los sustantivos afectan los procesos de otorgamiento de bienes y servicios. Por ejemplo, un instrumento procedural puede ser un ejercicio de referéndum, en donde el gobierno hace uso de éste para obtener opiniones del público. Un instrumento sustantivo puede ser una ley, como la Ley del Equilibrio Ecológico y la Protección al Ambiente, en la que se establece lo que la sociedad debe hacer en términos de protección al medio ambiente y cómo se regula el número de permisos para contaminar. Bajo este razonamiento, identificamos a los procesos multiparticipativos y a las coaliciones ambientales dentro del marco global de

\footnotetext{
${ }^{10}$ Los instrumentos regulatorios no pueden ser utilizados por la ciudadanía a menos que sea a través de un litigio, ya que la ley es impuesta por los gobiernos. Sin embargo, dicha ley debería (en teoría) tener un sustento sobre la decisión de la sociedad en general. El mismo caso ocurre con los instrumentos económicos.
} 
modalidades procedurales, ya que influyen las políticas ambientales a través de procesos cooperativos y de consenso.

Adoptamos en el presente trabajo la misma tipología de instrumentos de política pública que en un trabajo anterior (VegaLópez y Pacheco-Vega, 2000), en el que diferenciamos tres generaciones de instrumentos: la reglamentación tradicional (mandato-control o comando-control, primera generación o 'palos'), los incentivos económicos o instrumentos basados en el mercado (segunda generación o 'zanahorias') y los instrumentos suasivos (tercera generación o 'sermones'). Debe recordarse, sin embargo, que estos instrumentos pueden verse mezclados o compartir características de uno y otro modelo (por ejemplo, un acuerdo voluntario en el que existe una sanción inherente o invisible, se convierte en un instrumento mixto de regulación-suasión). A continuación, analizamos los niveles de la participación ciudadana en la consecución de los objetivos del desarrollo sustentable (enmarcados en Agenda 21).

\section{Modalidades de participación ciudadana}

Existen diversos niveles de participación (algunos reales y otros, más que una realidad, son objetivos a alcanzar, aun en una sociedad del siglo xxI). Una perspectiva teórica sobre los distintos niveles y las modalidades de participación la ofrece Sherry Arnstein en su artículo de 1969, en el cual establece una «escalera de participación ciudadana» (véase el esquema I). Arnstein argumenta que la participación ciudadana sigue una escala ascendente, en la cual los peldaños del fondo (terapia y manipulación) son los niveles en los que no existe participación, el gobierno manipula y proporciona terapia a 'Juan Pueblo'. En los niveles intermedios (grados de mantenimiento-consulta, aplacamiento e información), existe todavía una cierta tendencia a no incluir la voz del público en la toma de decisiones; sin embargo, la participación ciudadana se hace más significativa, y el público toma el papel de consejero del gobierno. En los niveles máximos (alianza, poder delegado y control ciudadano), se pretende que el ciudadano gobierne junto con el gobernante. Es un objetivo utópico. Sin embargo, este es el objetivo de las sociedades democráticas y de la sustentabilidad: lograr que el ciudadano gobierne. 


\section{Esquema I \\ La escalera de participación de Arnstein}

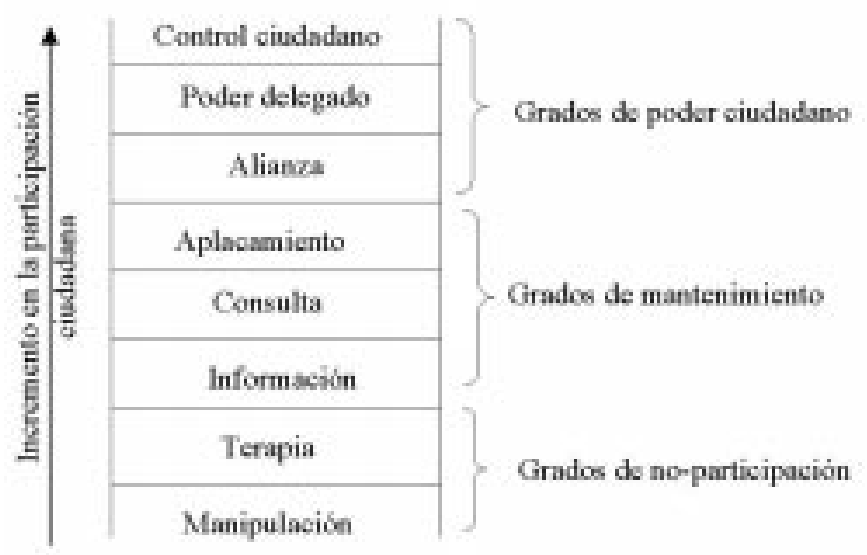

Fuente: Arnstein, 1969.

Obviamente, distintas modalidades de participación ciudadana tienen distintos niveles de impacto en el proceso de toma de decisiones en la formación de la política. Por ejemplo, es notable que el impacto de los niveles de no-participación es nulo. Sin embargo, a pesar de los múltiples estudios que se han hecho sobre participación ciudadana, no existe una forma de medir, de manera más o menos cuantitativa, el grado de penetración en el gobierno o el nivel de influencia de las modalidades de participación ciudadana en la política pública. Sin embargo, en teoría, podría esperarse que la política pública esté orientada hacia la sustentabilidad si las modalidades de participación ciudadana se encuentran en los niveles superiores (es decir, en los grados de poder ciudadano).

Establecemos a las CA y a los PMP dentro de los grados de mantenimiento y de control ciudadano por dos razones: primera, ambas modalidades de participación tienen el potencial para forjar alianzas con el gobierno (y por ende, lograr los niveles de participación más altos). Segunda, a pesar de dicho potencial, en ocasiones su papel se podrá ver limitado a labores de información, difusión y consulta (que si bien no es el ideal, es mejor que la no-participación). Por ende, es difícil ubicarlas en un solo nivel, y podrán oscilar desde el papel informativo hasta el control 
ciudadano y la transformación del gobierno. ${ }^{11}$ En las siguientes secciones describimos más a profundidad nuestros conceptos de CA y de PMP.

\subsection{El papel de la participación ciudadana en el desarrollo sustentable}

En el campo del derecho y la política pública ambiental, la acción ciudadana juega un papel preponderante. Algunos aspectos de esta actividad incluyen:

- El involucramiento en la formulación y puesta en marcha de la política ambiental.

- La participación en el proceso de toma de decisiones para la aprobación de permisos de desarrollo y construcción de nuevas entidades manufactureras y productivas, control de niveles de contaminación, y proyectos de inversión.

- El establecimiento de estándares (normas) de niveles de contaminación en casos de industrias particulares.

- El monitoreo de desarrollos productivos tanto privados como públicos para asegurar el cumplimiento de las normas ambientales.

- Aspectos coercitivos (hacer valer la ley ambiental) así como sanciones ambientales.

Anteriormente, la participación ciudadana en el área de derecho y política ambiental se había llevado a cabo a través del involucramiento de ciudadanos en la acción política de ONG, el llamado lobbying o cabildeo, para tratar de influir en la política y toma de decisiones. En la actualidad, la organización de la acción colectiva en forma de coaliciones ambientalistas u ONG es una modalidad más refinada de participación y cabildeo. En algunas jurisdicciones, los ciudadanos (de manera individual) pueden tomar acción para forzar a las agencias o dependencias gubernamentales a actuar en materia ambiental; en el estado de Guanajuato, un ejemplo claro son los procesos en los que el ciudadano presenta una denuncia en materia ambiental contra empresas contaminan-

${ }^{11}$ Cabe recalcar que la única manera eficaz de determinar la localización de ambas modalidades de participación en la escalera de participación de Arnstein sería a través de un estudio empírico de casos -preferentemente con múltiples casos y múltiples niveles y escalas de participación-, lo cual obviamente presenta grandes dificultades metodológicas. Aquí no hacemos este tipo de análisis empírico, sino un estudio argumentativo lógico de la literatura y desarrollamos propuestas propias. 
tes; dichas denuncias son presentadas en instancias como la Delegación Estatal de la Procuraduría Federal de Protección al Ambiente y la recientemente creada Procuraduría Estatal de Protección al Ambiente, que son las encargadas de velar por el cumplimiento de las empresas en materia de control de la contaminación.

Vega-López y Pacheco-Vega $(2000,2001)$ consideran que la política pública se lleva a cabo a través de un proceso por etapas, cada una de las cuales posee sus actores, restricciones, decisiones, desarrollos y resultados propios. Este marco analítico ha sido estudiado por diferentes autores, pero todos coinciden en que se lleva a cabo en etapas definidas. Este es uno de diversos enfoques (más o menos homogéneos y uniformes) para la formulación de política y, de tal suerte, sigue un procedimiento ordenado, lógico y razonado para atacar problemas de índole pública. En teoría, este tipo de estructura de construcción de políticas debería funcionar en cualquier contexto, sea política de salubridad, nutrición, mineral o ambiental. Sin embargo, la política ambiental tiene aspectos muy peculiares: su carácter global (que está implícito en la misma naturaleza de los problemas ambientales) ha cobrado notoriedad, gracias a la creciente presión internacional sobre países en una etapa relativamente temprana; es decir, dicha presión llega a los países aun antes de que exista suficiente acumulación de recursos para 'jugar el juego' de la protección ambiental internacional. La interacción en el esquema global no deja de tener implicaciones (un ejemplo claro es el Tratado de Cooperación Ambiental de América del Norte y la controversia entre comercio y medio ambiente), y el contexto nacional de los problemas ambientales ha sido claramente rebasado. Adicionalmente, el establecer una agenda de política ambiental cada vez es un proceso menos estructurado ya que es necesario tomar en cuenta actores políticos y sociales que no se encuentran dentro de fronteras geográficas nacionales; por ello, la política ambiental nacional ve minimizada su efectividad.

La necesidad de nuevos instrumentos de política proviene de este conflicto de intereses: por un lado, la limitada capacidad nacional para lidiar con los problemas de índole ambiental, y por otro, la presión internacional para tomar acciones que minimicen los efectos negativos de un deficiente cuidado del entorno. El gobierno requiere nuevas formas de atacar tanto los problemas ambientales de antaño como los actuales, para proveer respuestas satisfactorias a conflictos que el mismo gobierno ha creado. 
Un ejemplo de enfoques previamente utilizados para el análisis de políticas es el uso de herramientas analíticas de la microeconomía aplicada (considerando los problemas de índole ambiental como resultado de un mercado que falla). La teoría microeconómica considera los problemas de contaminación ambiental como un caso de externalidades. Los instrumentos económicos están fundamentados precisamente en la formación de incentivos para que las firmas internalicen sus externalidades.

Existen diversas razones por las que los instrumentos económicos no son utilizados de manera más amplia. Dichos obstáculos pueden ser procedurales, institucionales o estructurales; sin embargo, lo más importante es que, en su conjunto, limitan la efectividad de la adopción de los instrumentos económicos antes mencionados. La idea de que el gobierno es un actor único, racional, indivisible, con información perfecta y que no incurre en costos al tomar o hacer valer decisiones es una falacia, ya que el gobierno no funciona como una entidad teórica y abstracta. Las agencias gubernamentales responsables de la formulación y puesta en marcha de intervenciones públicas son varias, diferentes y en muchas ocasiones están en conflicto una con la otra. Aún más importante, dichas agencias están compuestas por personas que tienen herramientas, ideas e intereses muy diversos, que en ocasiones se ven confrontados y no siempre existe un consenso de opinión.

Es necesario aclarar que si bien la Secretaría del Medio Ambiente y Recursos Naturales ha trabajado extensivamente en la introducción de los instrumentos económicos como una alternativa de política ambiental orientada hacia el desarrollo sustentable, en la actualidad los nuevos enfoques de construcción de políticas sugieren involucrar nuevos actores, que tengan el efecto de cambiar la forma en la que el juego de la política ambiental se lleva a cabo. Estos instrumentos, que hemos denominado de tercera generación, forman parte de un acervo de herramientas específicas que contribuyen a incrementar la participación de la ciudadanía en la política pública. Un ejemplo de ello es la incorporación de formas de acción ciudadana, que incrementa el número de personas que actúan en defensa del ambiente; de esta manera, las entidades potencialmente contaminantes se involucran en un proceso contractual y colaborativo en el que se establecen las garantías a las que tiene derecho el ciudadano (entre ellas, el que se ha dado en llamar derecho al desarrollo sustentable) de suerte que sea él un 'vigilante' del cumplimiento de las 
empresas en materia ambiental. Tanto la formación de coaliciones de ONG ambientalistas como el modelo multiparticipativo de mesas redondas, forman parte de un conjunto de nuevos enfoques de involucramiento ciudadano en la construcción de política, y ha cobrado gran relevancia en el área ambiental. Consideramos que este es el surgimiento de un nuevo paradigma, el de democracia para la sustentabilidad.

\subsection{Instrumentos promotores de participación ambiental}

En muchos casos de control de contaminación, y más aún, cuando se trata de conservación y mejora ambiental, existe conflicto de intereses; la imposición de reglas por parte del Estado no es la única ni es siempre la mejor opción. Por el contrario, la mayor parte de los conflictos tienen el potencial para resolverse de manera consensual a través del acuerdo entre los interesados, incluyendo los representantes del interés público. De la misma forma en que ciertos acuerdos de negocios se alcanzan a través de la intervención de una tercera entidad que es capaz de reducir los costos de transacción, en política ambiental también es posible desarrollar un proceso de mediación a través de la selección de un árbitro neutral que tendrá la responsabilidad de diseñar el procedimiento adecuado para resolver disputas y presidir las mesas de trabajo.

La introducción de mediadores en asuntos ambientales es un instrumento de política novedoso. Está directamente orientado hacia la redefinición de los patrones de interacción entre las partes interesadas, creando las condiciones de confianza y credibilidad mutua que pueden facilitar la construcción de consenso. Más aún, los procedimientos de mediación se pueden interpretar como un proceso de aprendizaje social, que tendrá efectos permanentes en la forma en la que los actores se relacionarán entre ellos mismos en el futuro. De esta manera, es posible decir que el modelo multiparticipativo (mesas redondas de mediación) es un nuevo instrumento de política regulatoria basado en el entendimiento de la forma en la que interactúan los actores políticos y, de manera especial, los involucrados (grupos de interés) en el asunto o conflicto de índole ambiental; este instrumento promueve la participación ciudadana en el marco de una visión democrática para el manejo sustentable de los recursos naturales. Los enfoques previamente citados han propiciado un incremento en el nivel de participación ciudadana; de la misma manera, el 
enfoque multiparticipativo tiene como fin el hacer partícipes a todos los actores que tienen un interés en (y en cierta forma, que son afectados por) un problema de índole ambiental. Este modelo es descrito en secciones posteriores.

\section{Coaliciones ambientales}

En el presente trabajo, consideramos que todas las coaliciones se encuentran formadas por organizaciones que no son lucrativas ni gubernamentales, por tanto, las denominaremos ONG. Reconocemos que pueden existir individuos sin una afiliación específica a una ONG que participan en una coalición, y que miembros de la academia y de los cuerpos científicos pueden formar parte de dichas coaliciones. Sin embargo, las coaliciones de científicos son denominadas comunidades epistémicas y analizadas extensivamente en la literatura sobre relaciones internacionales y de cooperación.

Para fines de este ensayo, limitamos nuestra definición de coalición a grupos de personas y a personas que pertenecen a una ONG. La participación de las ONG en la vida pública es no sólo relevante sino vital para mantener un proceso político transparente. Al tomar representación de los intereses de la sociedad ampliada, las ONG establecen relaciones con los diversos actores que permiten a los ciudadanos monitorear y regular las actividades tanto de los intereses empresariales como de los elementos gubernamentales. La función de supervisión (watchdog) de las ONG ha sido descrita extensamente en numerosos ensayos en la literatura sobre el llamado 'tercer sector'. Hay diversas ramas teóricas de las ciencias sociales que examinan a los grupos de ONG a través de encuadres analíticos muy variados. Por ejemplo, las teorías de relaciones internacionales examinan el papel de las ONG como actores políticos que intervienen en las interacciones transnacionales, tomándolas como actores no-estatales (es decir, todos aquellos actores que no son el Estado-Nación). El énfasis en cooperación internacional a través de estos actores ha sido notorio en la literatura teórica. Los trabajos analíticos sobre ONG ambientalistas y las relaciones transnacionales que establecen para ejercer influencia en la esfera de política ambiental nacional e internacional forman parte de la nueva literatura sobre relaciones internacionales ambientales. Entre éstos podemos citar los 
trabajos de Paul Wapner en la esfera internacional y de Blanca Torres de El Colegio de México en la literatura mexicana. ${ }^{12}$

La teoría sociológica examina la formación de redes de organizaciones a través de perspectivas teóricas como la movilización de recursos (MR) y el enfoque de nuevos movimientos sociales (NMS). Las coaliciones son, entonces, redes intrincadas de organizaciones e individuos que colaboran para la solución de un asunto específico (grievance). ${ }^{13}$ En resumen, las ONG y otras modalidades de movimientos de participación son fenómenos sociales que se forman con el fin de atacar un problema desde una perspectiva colectiva y producir un cambio social. Los movimientos sociales tienen objetivos comunes, pueden ser internamente muy diversos y tener un nivel de tensión especial entre su espontaneidad y estructura. Un movimiento social se conforma a partir de cuatro elementos: una red de participantes, un asunto a resolver, un incidente que precipita la movilización y la habilidad de los participantes en el logro de la movilización. Frecuentemente dicha movilización involucra coordinación y cohesión entre grupos.

Existe un gran número de teorías que examinan los movimientos sociales; podemos distinguir dos ramas primordiales: positivistas, de manera muy relevante la teoría de movilización de recursos (TMR) y la teoría de procesos políticos (TPP), que son teorías sociales-estructurales que explican el surgimiento de movimientos sociales como el resultado de fuerzas exógenas a los individuos; y por otro lado, las teorías constructivistas y posmodernistas, donde se ubican las teorías de nuevos movimientos sociales (TNMS), que enlazan conceptualmente cultura, ideología e identidad para explicar cómo nuevas identidades surgen como resultado de los movimientos sociales.

Las TMR identifican a los participantes como actores racionales que actúan en busca de su propio interés y movilizan recursos para adelantar su posición y ganar terreno en las negociaciones con otros grupos. ${ }^{14}$

La ciencia política considera a las ONG y a las redes de estas organizaciones bajo diversas perspectivas teóricas. Dos aproxi-

${ }^{12}$ Véanse Wapner (2000) y Torres (1999), quien también ha escrito sobre la formación de coaliciones de ONG y su influencia en la negociación del TLCAN.

${ }^{13}$ La literatura sociológica sobre movimientos sociales es abundante y no nos atreveríamos a aventurar que nuestra breve descripción hará justicia a la riqueza de perspectivas. Por ende, sugerimos que una excelente fuente para conceptos teóricos es Zald and McCarthy (1987).

${ }^{14}$ El artículo de Aranda (2000) sobre movimientos estudiantiles es un excelente trabajo que examina estas teorías de movimientos sociales. 
maciones iniciales son la teoría de grupos de interés (TGI) o interest group theory y la teoría de redes de política (TRP) o policy networks. La TGI argumenta que existen muchos grupos de interés que compiten para controlar la política gubernamental, y que sus intereses en conflicto se contrapuntean y balancean de manera que proveen un buen gobierno. En este sentido, las coaliciones se forman como resultado de intereses homogéneos y coherentes de diversos grupos de interés, para ganar poder político y lograr contrapesar intereses opuestos. Por su parte, la TRP establece que la política pública se lleva a cabo no en una rígida estructura jerárquica donde el gobierno está en la cúpula y los grupos de interés se encuentran en el fondo; por el contrario, se lleva a cabo en un entretejido o red de actores y grupos. Por ejemplo, Martínez (1996: 45) establece que las redes de políticas son "grupos relativamente estables de organizaciones o actores públicos o privados conformados en alianzas para promover o defender los intereses colectivos de todos (intereses comunes) o de una parte (establecimiento de prioridades) de los miembros de un sector a través de la negociación. Son sistemas horizontales de coordinación entre empresas, agencias de la administración pública y asociaciones (empresariales y civiles) que a pesar de que no son impuestas ni están jerárquicamente organizadas, son más estables que las formas que se basan en el funcionamiento del mercado".

La literatura sobre participación ciudadana se ubica en los contextos teóricos de conformación de organizaciones sociales, formación de coaliciones internacionales, teorías de movimientos sociales y la formación de capital social. En nuestro análisis, la intención no es hacer una síntesis teórica de las diversas disciplinas (la cual se requiere, pero sería objeto de un trabajo posterior). La perspectiva de este trabajo es distinta y el análisis está centrado (si bien evidentemente teórico y argumentativo) en los PMP y las CA y su intervención en el ciclo de política pública (desde el establecimiento de la agenda hasta la implantación), un análisis que utiliza el encuadre analítico de la teoría de instrumentos de política pública. En trabajos anteriores hemos detallado el papel de los instrumentos de tercera generación en la construcción de una política pública orientada hacia la sustentabilidad (Vega-López y Pacheco-Vega, 2000: 33). En este artículo, avanzamos dicha noción un paso más, describiendo dos de las modalidades más utilizadas para la participación del público en política ambiental. De este modo, analizamos el papel de las coaliciones ambientales y los procesos multiparticipativos en un espectro de 
opciones de política pública disponibles para los gobiernos (específicamente, el gobierno mexicano). Sin embargo, notamos que este tratamiento es una práctica no convencional y llena un vacío en la literatura sobre instrumentos de política ambiental, al complementar los análisis exhaustivos que ya se han hecho sobre instrumentos de primera generación (regulación o comando/control) y de segunda generación (incentivos financieros). ${ }^{15} \mathrm{Al}$ analizar estos instrumentos de política en el contexto de una política pública orientada hacia la sustentabilidad, es posible determinar su viabilidad y factibilidad no sólo técnica, sino política y social.

Definimos coalición como un grupo compuesto de diversas organizaciones, facciones y formaciones, que se juntan o coalínean para llevar a cabo un objetivo específico. Una coalición se forma, usualmente, como respuesta a una necesidad en una comunidad en específico. Las coaliciones pueden variar en cuanto a objetivo, propósito, intensidad y duración dependiendo de la comunidad y de la necesidad. Algunas coaliciones se forman para compartir información, ideas, etcétera. Otras pueden formarse para resolver un problema en particular. Las coaliciones cuentan con la ventaja de que pueden tener mucha mayor credibilidad que las organizaciones individuales. También pueden desarrollar un grado superior de apoyo, mayor al que una organización única pueda obtener. De esta manera, pueden incrementar su visibilidad y la percepción del público de la relevancia de los asuntos que tratan de resolver. En el presente trabajo analizamos el papel de las coaliciones de ONG ambientalistas en los ámbitos nacional e internacional (sin utilizar la perspectiva de cooperación, sino bajo la modalidad de participación ciudadana).

Existen diversas ventajas en la construcción de coaliciones. Cuando una organización puede identificar que por sí sola no tiene las capacidades técnicas o los recursos humanos para resolver o, al menos, tener un impacto en un asunto en particular, puede decidir que es el momento de formar una coalición. Los asuntos ambientales son complejos y los públicos a los cuales hay que llegar, mucho mayores. Frecuentemente, con el fin de lograr un objetivo, la representación debe abarcar un área mucho mayor y, por tanto, es necesario incluir grupos con los que anteriormente no se habían formado alianzas.

\footnotetext{
${ }^{15}$ Para una revisión de la literatura en español sobre comando-control, véase Brañes-Ballesteros (1994). Para una revisión de incentivos financieros, véase el excelente libro de Alfonso Mercado (comp.) (1995).
} 


\subsection{Ventajas de las coaliciones ambientales}

- Es probable que una coalición pueda ganar en más de un frente, ya que una organización que trabaja sola puede atacar únicamente en un frente a la vez.

- Actuando con un efecto multiplicador, una coalición incrementa el impacto de los esfuerzos que aporta cada organización.

- A través de las coaliciones, se puede incrementar el nivel de los recursos (y maximizar la eficiencia). Diversos grupos se pueden beneficiar de los recursos de los demás, y compartirlos, como espacio de oficina, equipo de cómputo, accesos a recursos adicionales, biblioteca, etcétera.

- Una coalición permite desarrollar nuevos líderes, ya que la diversidad y pluralidad de intereses representados en ella puede renovar las filas y la militancia.

- A través de las coaliciones es posible ampliar el ámbito de influencia de organizaciones, cuyo trabajo era primordialmente a escala local. Este ha sido, por ejemplo, el caso de ONG nacionales que forman coaliciones con otras internacionales (Greenpeace, Environmental Defense, World Wildlife Fund, etcétera).

\subsection{Desventajas de las coaliciones ambientales}

- La participación en una coalición puede aumentar las posibilidades de distracción por trabajos de otro tipo (por ejemplo, una ONG que trabaja sobre protección de fauna silvestre podría empezar a hacer trabajo sobre mariposas monarca). Aun cuando potencialmente pudiera ser un beneficio, la multiplicidad de trabajos puede producir resultados subóptimos.

- Dado que existe una diversidad de ONG participando con un nivel distinto de recursos, la coalición es únicamente fuerte en tanto tenga participantes con una base sólida de recursos que aportar. De lo contrario, existe el peligro de que la coalición se disuelva.

- El principio de veto (un grupo, un voto) que es por excelencia democrático, puede no ser bien recibido por todos los miembros de la coalición, ya que privilegia grupos que en ocasiones no pueden aportar el mismo nivel de recursos. 
- La coalición se lleva la mayor parte del crédito si el trabajo no es acreditado también en las organizaciones individuales.

Como en todo trabajo académico, siempre queda la pregunta analítica: ¿qué fenómeno se está tratando de explicar? En el presente caso, intentamos más que explicar la formación de coaliciones (cómo y bajo qué condiciones), describir su papel como mecanismos de participación ciudadana. Sin embargo, la pregunta acerca de la formación de coaliciones resulta muy interesante, y la exploramos brevemente.

Las teorías de movimientos sociales argumentan que la movilización de recursos y la acción colectiva generan cambios sociales. Dicha acción colectiva puede incluir la conformación de redes de organizaciones (coaliciones) para resolver los asuntos en conflicto. Por otro lado, la teoría de redes de política pública señala que las redes de política se forman como respuesta a la complejidad y multidimensionalidad de los problemas de política pública. Los dilemas en torno a sustentabilidad y medio ambiente son complejos y multidimensionales. Por ello, es posible argumentar que las coaliciones ambientales se forman como resultado de la complejidad inherente de los problemas ambientales, y pueden formar parte de una red de política pública mayor.

Estas perspectivas teóricas explican, en parte, el surgimiento de las coaliciones ambientales; sin embargo, existe una tercera perspectiva, abordada por Pacheco-Vega (1998, 1999), que es la perspectiva de complementariedad, según la cual las alianzas estratégicas son el resultado del reconocimiento por parte de las diversas organizaciones, de su incapacidad para maximizar sus ganancias por sí mismas. Por ende, reconociendo que los activos que puedan tener otras organizaciones son complementarios, las organizaciones tienden a buscar una simbiosis en la que los recursos que cada una aporta complemente a la otra. Esta perspectiva simbiótica no es puramente altruista, por el contrario, en ocasiones asume una perspectiva de selección racional (como agentes microeconómicos puramente egoístas). Sin embargo, la perspectiva de la complementariedad permite avanzar en el entendimiento de por qué se forman las coaliciones ambientales. Se puede entonces inferir que las coaliciones ambientales se forman ya que las ONG participantes buscan complementar recursos para avanzar sus posiciones. El ejercicio de formación de coaliciones es, entonces, un ejercicio de búsqueda de activos complementarios 
(Pacheco-Vega, 1998). En la siguiente sección describiremos otra modalidad de participación ciudadana en la que existe la cooperación entre agentes, los PMP.

\section{Procesos multiparticipativos}

Los PMP se han convertido en la 'marca registrada' del movimiento del desarrollo sostenible; ${ }^{16}$ estos procesos conjuntan diversos grupos de interés para ayudar a establecer agendas, resolver conflictos e incrementar el intercambio de información; varios factores han llevado a que esta herramienta incremente su popularidad, entre ellos podemos citar:

- El surgimiento de procesos de toma de decisión más participativos en diversos países (por ejemplo, Canadá y Estados Unidos). Esta dinámica está asociada con la transferencia de poder hacia la gente que se encuentra en la base de los conflictos ambientales. Un ejemplo es el papel de las ong en la Cumbre de Río, la Cumbre Río+5 y la Cumbre de la Tierra (2002).

- El advenimiento de aspectos ambientales y cuestiones científicas que involucran grandes niveles de complejidad, riesgo e incertidumbre; por ende, se ha buscado el apoyo científico y de organizaciones involucradas para sustentar las decisiones políticas.

- Los impactos ecológicos, sociales, políticos y económicos a escala global son ya bastante significativos y los grupos afectados querrán verse involucrados en la construcción de políticas orientadas a la solución de dichos impactos de manera sustentable.

Los PMP incrementan el apoyo sectorial y ayudan a que las decisiones sean más duraderas; pueden, asimismo, incrementar la aceptación de la política pública que es desarrollada a través de este tipo de procesos. De esta manera, los representantes políticos cuentan con herramientas innovadoras y propositivas, de suerte que su toma de decisiones en el terreno legislativo sea más efectiva. Una de las razones por las que este modelo resulta efectivo es porque tiene el potencial de reducir conflictos socio-políticos, ya que incrementa el entendimiento entre los distintos sectores. De esta misma manera, los representantes y encargados de trabajo.

${ }^{16}$ Los conceptos sostenible y sustentable se utilizarán de manera indistinta en este 
elaborar las políticas pueden entender todas las implicaciones y relevancia que tiene un asunto determinado.

Sin embargo, si los participantes carecen de información de buena calidad, o de herramientas para llegar a un consenso, sus decisiones no serán más sustentables que aquellas obtenidas por procesos menos participativos. Los PMP tienen el riesgo de que si las mesas redondas no están conformadas por personas informadas y con habilidad para llegar a un consenso, pueden originar conflictos.

El diálogo multiparticipativo requiere un moderador con la habilidad de establecer una atmósfera de cordialidad, confianza y debe ser, asimismo, capaz de asegurar que todas y cada una de las voces participantes sean escuchadas. Dicho moderador debe también enfocarse en las necesidades humanas y no en posiciones políticas rígidas y carentes de flexibilidad. Además, para que los procesos basados en consenso (por ejemplo, PMP) tengan un impacto duradero, se requiere que las negociaciones en las mesas redondas estén basadas en principios que todos los participantes puedan aceptar. Uno de estos principios es el discurso razonado o discusión equilibrada entre los participantes; en la práctica, este concepto se relaciona directamente con la creación de consenso.

El concepto de consenso está definido con base en la unanimidad de opiniones, es decir, la construcción de consensos involucra el balanceo de intereses y valores. Las mesas redondas y otros mecanismos similares representan nuevos estilos de toma de decisiones, así como enfoques de gobierno innovadores. Como beneficio colateral, el sostener reuniones multiparticipativas periódicas durante un cierto tiempo puede redundar en una mejor relación de trabajo y los participantes en dichas mesas pueden ser llamados a colaborar nuevamente en grupos de trabajo similares, logrando llegar al consenso de manera más rápida y efectiva.

Las iniciativas de mesas redondas pueden servir como un foro para ayudar a mediar y mitigar disputas entre intereses específicos que se encuentran en conflicto dentro de la sociedad. Estos nuevos instrumentos de política tienen como propósito ayudar a la sociedad del siglo XXI, que frecuentemente se caracteriza por excluir a los ciudadanos de las decisiones que pueden afectar profundamente sus vidas. La consulta pública es a menudo considerada como una actividad necesaria para incrementar la legitimidad de los gobiernos y apaciguar demandas públicas en conflicto. Este es el caso particular con el desarrollo sustentable donde, de alguna manera, debemos encontrar un balance entre el medio ambiente y la economía; los ejercicios de mesas redondas, por 
tanto, constituyen un componente fundamental de las recomendaciones plasmadas en el reporte de la Comisión Brundtlandt "Nuestro Futuro Común”: “... un sistema político que asegure la participación efectiva de los ciudadanos en la toma de decisiones ...” (WCED, 1987). Como cualquier instrumento de política perfectible, el modelo multiparticipativo tiene ventajas y desventajas, que serán analizadas en las secciones subsecuentes.

Un PMP agrupa representantes de diversas extracciones y los reúne para desarrollar consensos y obtener soluciones duraderas y efectivas a sus problemas comunitarios. Por lo tanto, es un esfuerzo compartido por todos los afectados por o con un interés en el resultado de un problema para llegar a un entendimiento compartido y co-propiedad del asunto objetivo del conflicto, de manera que sea posible desarrollar soluciones a dicho problema e instrumentarlas. Este proceso emplea la construcción de consensos como herramienta para atacar problemas de comunidades sostenibles en formas innovativas que incluyen a todos los afectados por el problema; por tanto, los PMP son de especial utilidad en proyectos de comunidades sostenibles. Si bien una estrategia multiparticipativa puede no ser perfecta para todos los proyectos de comunidades sostenibles, frecuentemente es más apropiado para este tipo de proyectos que otras estrategias.

Los PMP pueden ser utilizados en cualquiera de las etapas del ciclo de construcción de políticas; por ejemplo, una de las actividades del ciclo que más se beneficia del PMP es el establecimiento de la agenda; sin embargo, su aplicación cubre muchas otras áreas. Los PMP son herramientas de formulación de política pública cuyo ámbito de aplicación más fuerte ha sido en aspectos de comunidades sostenibles, y como cualquier otra herramienta, tiene ventajas y desventajas. Si bien el PMP es un proceso de inclusión ciudadana en la toma de decisiones, no es una panacea: es una herramienta sólida de construcción de política pública ambiental, cuyas ventajas y desventajas se presentan a continuación.

\subsection{Ventajas del proceso multiparticipativo}

6.1.1 Involucramiento. Un PMP involucra todos los intereses relevantes al traer a la mesa de negociación representantes de todos los sectores ${ }^{17}$ con un interés relevante (a favor o en contra) del área a estudiar en el proyecto. Esto logra varios objetivos:

${ }^{17}$ Usualmente se utiliza un análisis transectorial. 
- El proceso ofrece un foro a todos los sectores que se han colocado en una actitud opositora, para identificar y discutir los asuntos relevantes fuera de un contexto adverso, tal como una corte o una cámara legislativa, donde frecuentemente sienten la necesidad de presentar una postura (en muchas ocasiones, desfavorable). Una discusión no restringida que incluya a las diferentes perspectivas en el asunto de interés puede conducir al descubrimiento de soluciones mutuamente aceptables.

- Si se pueden identificar soluciones conjuntas, el proceso multiparticipativo provee de un mecanismo para aprovechar los recursos y experiencia de todos los involucrados para poner en práctica estas soluciones.

- Al incluir una gran variedad de miembros dentro de una comunidad, se otorga prestigio y fuerza al proyecto, de manera que puede llamar la atención de los observadores y el público en general; lo que posibilita la obtención de más y mejores resultados, y la aceptación por parte del público de los productos de la negociación multiparticipativa.

6.1.2 Simultaneidad. Un PMP permite que todos los participantes puedan analizar aspectos interconectados al proyecto de manera simultánea. Por ejemplo, para analizar el desarrollo económico y la prevención de la contaminación de manera simultánea, el equipo multiparticipativo seguramente requerirá involucrar representantes de bancos, de las secretarías de desarrollo económico, corporaciones de desarrollo comunitario, ONG y grupos ambientales, así como participantes del público en general.

6.1.3 Inclusión. Un PMP garantiza que los estratos históricamente excluidos de la toma de decisiones hagan escuchar su voz de manera significativa en la mesa de toma de decisiones, ya que la premisa básica de un proceso multiparticipativo es incluir todas las perspectivas relevantes, considerando que el invitar afectados atípicamente representados otorga un avance importante al concepto de justicia social y ambiental, y amplía el rango de puntos de vista y la base sustentadora de un proyecto.

6.1.4 Incremento de conocimiento y conciencia. El PMP por sí mismo incrementará la base de conocimientos y la conciencia de los asuntos discutidos. Aun si el proyecto no es exitoso, el PMP 
provee de un mejor entendimiento a todos los participantes de las distintas posiciones con relación a un aspecto del proyecto.

6.1.5 Minimización de confrontaciones. Un PMP puede atacar un problema que ha sido o aún es de confrontación. Este tipo de proceso puede tener éxito en estas situaciones en el caso de que los participantes inviertan una gran cantidad de tiempo y esfuerzo identificando y justificando sus posiciones en un contexto que minimiza confrontaciones. El requisito más importante de un proyecto multiparticipativo es, por supuesto, un objetivo de proyecto compartido.

\subsection{Desventajas del proceso multiparticipativo}

6.2.1 Factor tiempo. Un PMP lleva tiempo, y frecuentemente (aunque no siempre) requerirá de más tiempo que otras estrategias. Los participantes necesitan educarse y compenetrarse de los valores del proceso mismo, aprender y conocer de las distintas facetas de un problema, desarrollar reglas de base ${ }^{18}$ y lograr un consenso.

6.2.2 Riesgo de errores operativos. Si no se lleva a cabo correctamente, un PMP puede conducir a una solución de 'denominador común’ poco satisfactoria. Se puede llegar a una pobre solución si los participantes sienten que una vez que un proceso improductivo inicia, debe de continuarse hasta que se llega a algún tipo de solución, aun cuando podría resultar mejor dar por terminado el proceso y reiniciar posteriormente.

\subsubsection{Identificación de problemas y soluciones en ámbitos ajenos.} Un PMP puede identificar problemas y soluciones bastante diferentes de aquellos que los participantes pudieron haber anticipado. Por tanto, esto puede hacer que las soluciones sean difíciles de poner en práctica; si existen soluciones que caen fuera del ámbito de trabajo de los participantes, la instrumentación puede ser muy difícil. Por ejemplo, si un grupo participante, cuyas habilidades están orientadas hacia el área ambiental o de salud, encuentra que las soluciones reales de un problema que han logrado identificar radican en prevención del crimen y educación, el

${ }^{18}$ Se define regla de base como 'las reglas del juego', el reglamento de la mesa redonda, los lineamientos que se seguirán en el desarrollo de la negociación. 
equipo puede carecer de las herramientas para satisfacer la instrumentación de las soluciones requeridas; por tanto, esto requerirá transferir el control a otro grupo de trabajo.

6.2.4 Trabajo en equipo. Un PMP requiere que los participantes trabajen juntos, aun cuando algunos no estén acostumbrados a trabajar en equipo, y mucho menos como colaboradores. Debido a que mucha gente no está acostumbrada a colaborar con quienes tienen perspectivas divergentes, puede resultar difícil desarrollar el nivel de confianza, credibilidad, entendimiento y soporte intragrupal que se requiere para que un PMP sea exitoso.

6.2.5 Necesidad de un mediador. Un PMP funciona mejor si es dirigido por un mediador con un perfil de personalidad específico. Este aspecto puede no ser percibido como importante, sin embargo, tiene una relevancia altísima. El líder de un PMP necesita tener paciencia, gran capacidad de escuchar y ser capaz de limar las asperezas en un grupo para lograr que los diversos participantes partan de la misma base y colaboren bajo los mismos lineamientos.

6.2.6 Carencia de coerción. Las soluciones que se alcanzan vía un PMP no son coercitivas de la misma manera que un decreto o un reglamento pueden serlo. Es posible que en un proyecto se llegue a excelentes soluciones e inclusive a comenzar la instrumentación sólo para encontrarse con que el proyecto se detiene porque uno o más de los representantes de los interesados cambia (por ejemplo, si la administración municipal cambia y el municipio toma parte en el PMP). No pasa lo mismo en el caso, por ejemplo, de la Ley del Equilibrio Ecológico y Protección al Ambiente; en este caso, dicha ley es de competencia federal y no requiere de aprobación por el gobierno municipal o estatal para su aplicación.

Uno de los cambios más significativos en la teoría de la administración pública y buen gobierno ha sido el cambio de una democracia representativa hacia una democracia participativa. Como menciona Vicencio Álvarez:

...debe reconocerse la pluralidad de intereses activos en las comunidades locales y la necesidad de tomar en cuenta a los grupos que los detentan en la construcción de convergencias que hagan de la gestión municipal algo verdaderamente público... (citado en Merino, 1996).

Reconociendo que las decisiones que incorporan diferentes intereses son más estables y duraderas, muchas agencias guberna- 
mentales han incorporado una extensiva participación pública en los procesos de toma de decisiones relacionados con áreas del interés de la sociedad. Como uno de los instrumentos de política que promueve la participación ciudadana, el PMP ofrece un foro en el que se analizan las distintas perspectivas de la comunidad para administrar los recursos (naturales, en el caso analizado en el presente trabajo) de manera más racional e integrada.

Generalmente, un PMP toma la siguiente forma: ya sea un grupo perteneciente a una comunidad o algunos grupos, necesitan identificar el problema genérico a analizar (desarrollo de la idea del proyecto). A continuación, se identifican y reclutan los participantes adecuados. Una vez que los participantes son reclutados, el equipo responsable del proyecto deberá desarrollar los lineamientos de base, y tomando en cuenta dichos lineamientos, el equipo puede iniciar el desarrollo del objetivo compartido del proyecto, el cual cristaliza la idea original del proyecto. Una vez que todos los participantes están de acuerdo con este objetivo, el equipo necesita identificar los recursos que requiere para el proyecto y desarrollar una estrategia o plan de acción. Una vez que dicha estrategia se pone en marcha, el equipo de proyecto puede definir indicadores de progreso para determinar y evaluar si la estrategia está funcionando. Finalmente, el equipo del proyecto necesitará revisarlo de manera periódica, evaluar el progreso obtenido y realizar los ajustes necesarios al plan, a la estrategia, o inclusive a los objetivos del proyecto.

Se ha hablado anteriormente de que el PMP involucra la construcción de consensos; este término puede crear confusión. El consenso requiere un esfuerzo de buena fe de parte de todos los participantes para alcanzar acuerdo unánime en la manera de enfocarse hacia un objetivo compartido de proyecto. Esto no significa que no exista conflicto o que todos obtengan lo que quieren; más bien, quiere decir que pueden tomarse mejores decisiones si existe un esfuerzo sincero para entender las perspectivas de otros que están interesados en o son afectados por una decisión. Todos deberían ser capaces de asumir las decisiones resultantes de un proceso de construcción de consensos. La construcción de consensos trabaja mejor cuando existe un número modesto (no muy grande) de tomadores de decisiones que comparten ciertos objetivos básicos.

Los interesados o participantes son la columna vertebral del proceso multiparticipativo; un participante es cualesquier partido político, grupo de poder, distrito electoral o grupo de 
votantes, u otro interesado que pueda verse afectado por la resolución de un problema que sea atacado con el proyecto de sostenibilidad ambiental. Al involucrar a todos los participantes que se ven afectados por el problema, en particular aquellos que históricamente han quedado fuera del proceso de toma de decisiones, se pueden obtener soluciones más efectivas y duraderas. Un participante puede ser también un grupo cuya experiencia y conocimientos son esenciales para llegar a una solución efectiva. Se debe reclutar gente de todos los grupos que tengan distintas perspectivas sobre un proyecto, para traer a la mesa una visión global y multilateral. El gran reto (pero también donde radica el poder de este tipo de instrumento) es conjuntar a todos los participantes (cada uno con su peculiar punto de vista y opinión) para encontrar e instrumentar soluciones compartidas.

\section{Coaliciones ambientales y procesos multiparticipativos en perspectiva comparada}

El análisis previo presenta a las CA y a los PMP como modalidades de participación ciudadana que se encuentran en un espectro de nivel de influencia en las decisiones gubernamentales de menor (ninguna influencia o manipulación del público) a mayor (máxima influencia o control ciudadano). Sin embargo, ambas modalidades presentan diferencias importantes. En esta sección presentamos un bosquejo analítico de las diferencias entre ambas modalidades de participación.

Como describimos en el cuadro 1 , los procesos de múltiples participantes gozan del privilegio de influir en las decisiones gubernamentales desde adentro, ya que al menos uno de los participantes en la mesa redonda proviene del gobierno. De manera alterna, las coaliciones ambientales tienen un mecanismo de influencia externo, ya que forman redes de cabildeo con las que ejercen presión. Precisamente en la capacidad de influir el proceso de toma de decisiones desde adentro es donde reside el gran poder de los PMP.

Podría parecer paradójico que el peso específico del PMP sobre la decisión gubernamental es limitado si el mecanismo de presión es endógeno. Sin embargo, una posible explicación es que precisamente dado que el representante gubernamental está involucrado en el proceso, al regresar después de las negociaciones a dialogar con el resto de los representantes gubernamentales, es posible que su capacidad de implantar las decisiones toma- 
Cuadro 1

Diferencias entre PMP y CA vistas como modalidades de participación

\begin{tabular}{|lll|}
\hline & $\begin{array}{l}\text { Procesos } \\
\text { multiparticipativos }\end{array}$ & Coaliciones ambientales \\
\hline $\begin{array}{l}\text { Mecanismo de difusión de } \\
\text { la presión }\end{array}$ & Endógeno (interno) & Exógeno (externo) \\
\hline Constitución o membresía & $\begin{array}{l}\text { Plural, múltiples } \\
\text { participantes }\end{array}$ & $\begin{array}{l}\text { En general, representantes } \\
\text { de ONG/"think tanks" }\end{array}$ \\
\hline Instituciones de validación & Gobiernos nacionales & $\begin{array}{l}\text { Gobiernos de otras } \\
\text { naciones. }\end{array}$ \\
& & $\begin{array}{l}\text { Organismos } \\
\text { intergubernamentales. } \\
\text { Organizaciones } \\
\text { internacionales. }\end{array}$ \\
\hline $\begin{array}{l}\text { Peso específico en la } \\
\text { decisión gubernamental }\end{array}$ & Limitado a medio & Vigoroso \\
\hline $\begin{array}{l}\text { Escala de interacción en la } \\
\text { esfera de decisión }\end{array}$ & $\begin{array}{l}\text { Nacional } \\
\text { (local - regional - estatal - - } \\
\text { federal) }\end{array}$ & $\begin{array}{l}\text { Internacional } \\
\text { (regional - transnacional - } \\
\text { local) }\end{array}$ \\
\hline $\begin{array}{l}\text { Establecimiento de la } \\
\text { agenda de trabajo }\end{array}$ & $\begin{array}{l}\text { Por consenso entre todos } \\
\text { los participantes }\end{array}$ & $\begin{array}{l}\text { Mecanismos de decisión } \\
\text { dentro de la coalición }\end{array}$ \\
\hline
\end{tabular}

Fuente: Elaboración propia.

das en la mesa redonda no sea tan alta. En cambio, las coaliciones gozan del privilegio de ejercer presión sobre los gobiernos, y éstos a su vez, responden mucho a la presión social y de los medios masivos de comunicación. Por ende, su peso específico resulta mucho mayor que el de los procesos multiparticipativos.

En el cuadro 2 detallamos las diversas actividades y papeles que pueden tomar los dos mecanismos de participación ciudadana, desde la construcción de la agenda hasta su puesta en práctica.

Como puede apreciarse, ambas modalidades de participación ciudadana tienen una gran relevancia en todas las etapas del ciclo de política pública ambiental. El nivel en el que puedan aportar a las discusiones y/o ejercer influencia sobre las decisiones gubernamentales será función directa de su capacidad de transmitir el mensaje de la sociedad civil y permear la sensibilidad ciudadana. También es importante notar la diferencia de los integrantes en ambas modalidades: mientras que en una mesa redonda de múltiples participantes pueden estar, entre otros, el gobierno y la academia, es generalmente una regla tácita que las coaliciones están formadas por organizaciones del mismo género (ONG, académicos, think-tanks, etcétera). Ello también influye en sus estrategias para ejercer influencia. 


\section{Cuadro 2}

Actividades de los PMP y las CA en el ciclo de política pública

\begin{tabular}{|lll|}
\hline & $\begin{array}{l}\text { Procesos } \\
\text { multiparticipativos }\end{array}$ & Coaliciones ambientales \\
\hline $\begin{array}{l}\text { Construcción de la agenda } \\
\text { pública. }\end{array}$ & $\begin{array}{l}\text { Todos los participantes } \\
\text { tienen una voz en los } \\
\text { asuntos que formarán la } \\
\text { agenda. }\end{array}$ & $\begin{array}{l}\text { Pueden tener un nivel muy } \\
\text { alto de influencia en la } \\
\text { agenda pública (cabildeo). }\end{array}$ \\
\hline $\begin{array}{l}\text { Formulación de las } \\
\text { diversas opciones de } \\
\text { política pública }\end{array}$ & $\begin{array}{l}\text { Opciones obtenidas de } \\
\text { todos los participantes. }\end{array}$ & $\begin{array}{l}\text { Opciones que provienen de } \\
\text { las organizaciones } \\
\text { miembro son evaluadas y } \\
\text { todas, o un subgrupo de }\end{array}$ \\
& & $\begin{array}{l}\text { éstas, son presentadas al } \\
\text { organo de decisión. }\end{array}$ \\
\hline $\begin{array}{l}\text { Toma de decisión con } \\
\text { relación a las opciones de } \\
\text { política pública }\end{array}$ & $\begin{array}{l}\text { Interno a la mesa redonda, } \\
\text { en ocasiones, externo } \\
\text { (gubernamental). }\end{array}$ & $\begin{array}{l}\text { La decisión es tomada por } \\
\text { el gobierno. }\end{array}$ \\
\hline $\begin{array}{l}\text { Implantación de la política } \\
\text { pública }\end{array}$ & $\begin{array}{l}\text { Los participantes pueden } \\
\text { colaborar en la } \\
\text { implantación (ya que la } \\
\text { opción fue resultado de un } \\
\text { proceso de decisión } \\
\text { interno). }\end{array}$ & $\begin{array}{l}\text { Las coaliciones pueden } \\
\text { colaborar en la } \\
\text { implantación de la opción } \\
\text { decidida por el gobierno, o } \\
\text { pueden optar por no } \\
\text { participar. }\end{array}$ \\
\hline $\begin{array}{l}\text { Todos los participantes } \\
\text { pueden colaborar en los } \\
\text { ejercicios de evaluación. }\end{array}$ & $\begin{array}{l}\text { La evaluación puede ser } \\
\text { llevada a cabo por la } \\
\text { coalición misma o en } \\
\text { colaboración con el } \\
\text { gobierno. }\end{array}$ \\
\hline $\begin{array}{l}\text { Evaluación de la política } \\
\text { pública }\end{array}$ & & \\
& & \\
& &
\end{tabular}

Fuente: Elaboración propia.

\section{Conclusión}

En el presente artículo hemos examinado dos modalidades de participación ciudadana: la formación de coaliciones ambientales (primordialmente, de ONG ambientalistas) y el desarrollo de mesas redondas de múltiples participantes o PMP. En ambas modalidades se establecen esquemas de cooperación entre el gobierno y los diversos actores políticos. Las coaliciones ambientales analizadas en el presente trabajo se suponen conformadas por ONG ambientalistas, quienes tienen un papel preponderante en una saludable vida política democrática. Los procesos de múltiples participantes otorgan a una gran diversidad de actores la oportunidad de involucrarse en la ardua tarea de construir un modelo de política pública más accesible al público y más legítimo, democrático, y por ende sustentable.

Es una realidad que las ONG están jugando papeles catalíticos en la modificación de comportamientos corporativos más 
amigables al ambiente. Es una forma emergente de 'regulación civil', en la que la formación de coaliciones juega un papel decisivo para lograr establecer estándares de comportamiento corporativo responsable y sustentable. De la misma manera, la participación en mecanismos en los que existan actores de diversas etnias y constituencias, así como diferentes objetivos sociales y de desarrollo, permite establecer directrices hacia la consecución de objetivos de protección ambiental más altos.

La sustentabilidad tiene como prerrequisito (ya establecido en Agenda 21) la atención a las diferentes dimensiones del desarrollo sustentable: económica, social, política, cultural y ambiental. A través del examen riguroso de las modalidades de intervención en la política pública ambiental, es posible determinar mecanismos innovadores para el diseño e implantación de políticas que tengan una orientación netamente de sustentabilidad, ya que la biosfera con que contamos es sólo una y, de cara al siglo XXI, solamente a través de la participación de la sociedad en la solución de los problemas ambientales podremos dejar un legado a las futuras generaciones.

\section{Bibliografía}

Aranda Sánchez, J. M. (2000), "El movimiento estudiantil y la teoría de los movimientos sociales”, Convergencia, núm. 21, pp. 225-250.

Arnstein, Sherry R. (1969), "A ladder of citizen participation", Journal of the American Institute of Planning, 35(3), pp. 216-224.

Brañes-Ballesteros (1994), Derecho ambiental mexicano, Fundación Universo Veintiuno, Ciudad de México.

Cabrero Mendoza, Enrique (2000), "Usos y costumbres en la hechura de las políticas públicas en México: Límites de las Policy Sciences en contextos cultural y políticamente diferentes”, Gestión y Política Pública, 9(2), pp. 189-229.

Canto Sáenz, Rodolfo (2000), "Políticas públicas. Mas allá del pluralismo y la participación ciudadana”, Gestión y Politica Pública 9(2), pp. 231-256. 
De Bruijn, H. A. and H. A. M. Hufen (1998), “The traditional approach to policy instruments", B. G. Peters and F. K. M. van Nispen (eds.), Public Policy Instruments. Evaluating the Tools of Public Administration, Edward Elgar Publishing Inc., Cheltentham, UK, pp. 11-32.

Dukes, E. F. (1996), Resolving public conflict. Transforming community and governance, Manchester University Press, Manchester.

Howlett, Michael (1999), “Complex network management and the paradox of modern governance: A taxonomy and model of procedural policy instrument choice", Annual Meeting of the Canadian Political Science Association, Sherbrooke, P.Q.

Martínez Escamilla, Víctor Hugo (1996), “Las políticas públicas desde la perspectiva de las redes sociales: Un nuevo enfoque metodológico", Política y Cultura, otoño, núm. 7, pp. 37-60.

Méndez, José Luis (1996), "Reforma del Estado, democracia participativa y modelos de decisión", Politica y Cultura, otoño, núm. 7, pp. 7-35.

Mercado, Alfonso (comp.) (1995), Instrumentos económicos para un comportamiento empresarial amigable al ambiente, FCE, México.

Merino, Mauricio et al. (1996), Experiencias de buen gobierno municipal, Colegio Nacional de Ciencias Políticas y Administración Pública, México.

Pacheco, Raúl y Peter N. Nemetz (2001), «Business-not-as-usual: Alternative policy instruments for environmental management», Proceedings of the $5^{\text {th }}$ IRE Annual Workshop: Addressing the Knowledge Crisis in Water and Energy: Linking Local and Global Communities, The University of British Columbia, Institute for Resources and Environment, Vancouver, B.C. 
Pacheco-Vega, Héctor Raúl (1998), "A proposed theoretical model for the construction of strategic alliances in the biotechnology industry", Proceedings of the 1998 R\&D Management Conference: Technology Strategy and Strategic Alliances, R\&D Management, 30 de septiembre, Ávila, España.

- (1999), "Transferencia de tecnología en la industria curtidora: El modelo de alianzas estratégicas”, Memorias del XVI Encuentro Nacional de Curtiduría, 2 de marzo, León, Gto., México.

- María del Carmen Carmona-Lara y Obdulia Vega-López (2001), «The challenge of sustainable development», Peter N. Nemetz (ed.), Bringing Business on Board: Sustainable Development and the B-School Curriculum, University of British Columbia Press, Vancouver, BC, en prensa.

Renn, Ortwin, Thomas Webler y Peter Wiedemann (eds.) (1995), Fairness and Competence in citizen participation. Evaluating models for environmental discourse, Kluwer Academic Publishers, Dordrecth.

Thomas, John Clayton (1995), Public participation in public decisions. New skills and strategies for public managers, Jossey-Bass Publishers, San Francisco.

Torres, Blanca (1999), "Las ONG ambientalistas en las relaciones México-Estados Unidos”, Foro Internacional 39(4), pp. 453-478.

Vega-López, Obdulia (1999), Análisis comparativo de politicas públicas para el desarrollo sustentable de la industria minera: Un estudio de contraste binacional México-Canadá, Tesis de Maestría, Universidad Iberoamericana, Departamento de Ciencias Jurídicas y Políticas, León, México, $135 \mathrm{pp}$.

— y Héctor Raúl Pacheco-Vega (2000), “Zanahorias, palos y sermones: Una revisión de la teoría de instrumentos de 
política ambiental”, en Revista Mexicana de Legislación Ambiental, año 1, núm. 4, pp. 25-33.

— y Héctor Raúl Pacheco-Vega (2001), "El medio ambiente como un problema de política pública. La teoría generalizada de la política ambiental y su relación con la administración pública”, en: Revista del Instituto de Administración Pública del Estado de Guanajuato, año 2, núm. 4, en prensa.

Wapner, Paul (2000), «The transnational politics of environmental NGOs: Governmental, economic and social activism», en Pamela S. Chasek (ed.), The global environment in the Twenty-First century: Prospects for international cooperation, United Nations University Press, Tokyo, pp. 87108.

WCED (1987), Our common future, Oxford University Press, Oxford, uk.

Weimer, David L. y Aidan R. Vining (1989), Policy analysis. Concepts and practice, Prentice Hall Publishers, Englewood Cliffs.

Zald, M. N. and J. D. McCarthy (1987), Social movements in an organizational society: collected essays, Transaction Books, New Brunswick, N.J., U.S.A.

Enviado: 6 de mayo de 2001 Aceptado: 28 de junio de 2001 
